\title{
A DESCRIPTIVE STUDY TO ASSESS THE PATIENT SATISFACTION TOWARDS NURSING CARE PROVIDED TO LOWER LIMB INJURY PATIENTS IN SELECTED WARDS OF CMC AND HOSPITAL, LUDHIANA, PUNJAB.
}

\author{
Ms. Neeta Masih ${ }^{*}$ I Mrs. Seema Baranbas** \\ *B.Sc. (N) intern in College of Nursing, CMC \& Hospital, Ludhiana, Punjab. \\ **Guide, Lecturer, College of Nursing, CMC \& Hospital, Ludhiana, Punjab. \\ DOI: http://doi.org/10.47211/idcij.2020.v07i03.009 \\ Received $10^{\text {th }}$ June 2020, Accepted $25^{\text {th }}$ June 2020, Available online $10^{\text {th }}$ July 2020.
}

\begin{abstract}
:
Admission to hospital following a traumatic lower limb injury is undoubtedly a stressful life event. The objective of the study was to assess the patient satisfaction towards nursing care provided to lower limb injury patients, to compare mean satisfaction score of lower limb injury patient and to find out the relationship of patient satisfaction regarding nursing care with selected variables. Data was collected by using purposive sampling method in which 40 patients, 20 male and 20 female were taken in Orthopedics' ward in CMC \& hospital, Ludhiana, Punjab. Structured interview schedule was used to collect the data using 5 point likert scale. The gathered data was analyzed by calculating the mean, percentage and standard deviation. Major findings of the study reveals that the lower limb patients were highly satisfied (90.53\%) with nursing care. Patients satisfaction according to basic needs like information need, comfort need, recording of vitals, pain management, nutritional need, medical need, elimination need, personal hygiene, prevention of complications and social need. Patient's most satisfied need was comfort needs (95.9\%) and least satisfied need was information need (75.6\%). Relationship of patient satisfaction with selected variables are age group of 46- 55 years are most satisfied (95.1\%) and least satisfied age group of 26-35 (85.3\%), Female patients are more satisfied than male patients (92.2\%) and 89.9\%) respectively. Employed patients are more satisfied than unemployed (90.66\%) and (90.46\%) respectively. Married (90.8\%) are more satisfied than unmarried (89.7\%), illiterate (92.95\%) are more satisfied literate (87.59\%), patient residing in urban areas (91.1\%) are more satisfied than rural areas (89.8\%), patients with income group below 2000/- have highest satisfaction (92.5\%) and income group of Rs 5001$10,000 /$ - have lowest percentage score of (89.2\%), patients undergone for amputation have more satisfaction (91\%) and patients on traction has lowest satisfaction (90.3\%), patients hospitalized for more than 3 times have highest score (93.5\%) and those for $2^{\text {nd }}$ or $3^{\text {rd }}$ time have lowest score (87.8\%).
\end{abstract}

KEYWORDS: Patient Satisfaction, Nursing Care, Lower Limb Injury Patients. 


\section{INTRODUCTION}

The advent of modern technology has added a tremendous pace to our life. Today everybody is in hurry, we are eager to achieve instant results in the shortest possible span of time. This pre occupation with a fast track existence has added problems to our daily life style which is already overloaded. A split second diversion sends a man crashing into the lap of accidents which may result in injuries. Admission to hospital following a traumatic lower limb injury is undoubtedly a stressful life event. Both professional and personal experiences suggest that trauma and subsequent orthopedic surgery have profound effect on individual. However a few qualitative studies have been undertaken to elicit patient perspective of recovery. Patient has to cope with sudden onset of acute incapacitating pain, immobility and unexpected hospitalization. Progress in returning to normal is dependent on a multitude of factors including quality and health care received.

Motor vehicle accident and fall are the primary mechanism of injury. In case of lower limb the person is debilitated to such an extent that he is unable to perform his routine duties. The effected person be a student, a professional or a businessman finds himself severally constrained in matters of study, work or business. Besides being confined to bed there is a feeling of dependency, financial burden and person is unable to meet his personal hygiene needs and is unable to do anything for him. This is time when there is increase in needs of patient. Now a day's literacy rate of India is increasing people know about their right they know the fact that they are consumers in health care. So according to a consumer protection act (CPA) if they have any problem with health care they can seek justice in various consumer courts found all over India.

Basically each individual have 14 elementary needs and when patient is bed ridden he wants that each and every need should be fulfilled otherwise they don't get satisfied by the care provided to them. So it is the nurses' role to provide maximum satisfaction to the patient while he is hospitalized. Nursing is always directed to serve the health care needs of the society. Nursing originated with the desire to keep people healthy, as well as to provide comfort continuity of care. Today nurse deals with patient as a whole. The focus of nursing care has broadened from care in illness to care of people both in sickness and health.

Michael and Evan stated that "Nurses have long known their importance in patient satisfaction but they may not be aware that the patient satisfaction has been widely adopted as notable indicator of quality care and is a monitored regularly in many ways". A person who is bed ridden, may have question in his mind and fear related to his/her condition which can be removed by carefully listening and answering to his question and clarifying his doubts. Nurses are the only one who is present $24 \mathrm{hrs}$ with the patient. Thus patient will be more satisfied if nurses pay attention toward them and give proper explanation regarding their recovery.

Satisfaction of patient has long been popular for evaluating nursing care. Satisfaction research fulfills three distinct function description of patients experience, identification of strength and weakness in service, provision and evaluating of care. According to John Sitizia, Neilwood (1998) assessment of patient satisfaction has become widely accepted as legitimate and worthwhile approach to improve service quality.

\section{NEED OF STUDY}

Health is a positive dynamic thing and everyone desires it. It also is needed to attain satisfaction in one's life. Today's client is paying person and has the right to receive the cost effective treatment and care. Patient will expect maximum satisfaction. Moreover the today's client is very much aware of customer protection Act which is a means to protect the patient against negligent nurse practitioners.

Nursing is always directed to maintain up to date knowledge and be aware of the technological advancement occurring daily to bring protection and highest level of satisfaction. 


\section{STATEMENT OF PROBLEM}

"A descriptive study to assess the patient satisfaction towards nursing care provided to lower limb injury patient in selected wards of CMC. \& Hospital, Ludhiana, Punjab.

\section{PURPOSE OF THE STUDY}

To assess patient satisfaction regarding nursing care of lower limb injury patient.

\section{OBJECTIVES}

1. To assess the level of patient satisfaction regarding nursing care of lower limb injury patient.

2. To assess patient satisfaction according to basic needs.

3. To identify the areas of most and least patient satisfaction.

4. To find out relationship of patient satisfaction regarding nursing care with the following variables such as:- Age, Gender, Educational status, Occupation, Marital status, Place of living. Economic status, Number of hospitalization, Type of treatment.

\section{METHODOLOGY}

Research approach: Descriptive approach

Research design: Non experimental

Setting of the study: the study will be conducted in selected Hospital of CMC Ludhiana, Punjab.

Population: All the patients who are admitted in orthopedics wards with lower limb injury.

Sample: lower limb injury patients who are admitted in orthopedics wards.

Sampling Technique: was purposive sampling.

Development of Tool: the tool was developed according to

- Consultation with 7 experts of field.

- Review of literature.

- Investigators interview of patients in ward.

- Investigators own experience in wards provided basis for contrition of tool.

\section{MAJOR FINDINGS}

Major findings of the study reveals that the lower limb patients were highly satisfied (90.53\%) with nursing care. Patients satisfaction according to basic needs like information need, comfort need, recording of vitals, pain management, nutritional need, medical need, elimination need, personal hygiene, prevention of complications and social need. Patient's most satisfied need was comfort needs (95.9\%) and least satisfied need was information need (75.6\%). Relationship of patient satisfaction with selected variables are age group of 46- 55 years are most satisfied (95.1\%) and least satisfied age group of 26-35 (85.3\%), Female patients are more satisfied than male patients (92.2\%) and $89.9 \%$ ) respectively. Employed patients are more satisfied than unemployed $(90.66 \%)$ and $(90.46 \%)$ respectively. Married $(90.8 \%)$ are more satisfied than unmarried $(89.7 \%)$, illiterate (92.95\%) are more satisfied literate (87.59\%), patient residing in urban areas (91.1\%) are more satisfied than rural areas (89.8\%), patients with income group below 2000/- have highest satisfaction (92.5\%) and income group of Rs 5001- 10,000/- have lowest percentage score of (89.2\%), patients undergone for amputation have more satisfaction (91\%) and patients on traction has lowest satisfaction (90.3\%), patients hospitalized for more than 3 times have highest score $(93.5 \%)$ and those for $2^{\text {nd }}$ or $3^{\text {rd }}$ time have lowest score (87.8\%).

IMPLICATIONS: Nursing Education Emphasis should be given on health education regarding the Mobilization aids, exercise and medications.

CONCLUSION: Overall the satisfaction score was $90.53 \%$. It shows that patients were highly satisfied with nursing care provided to them. 


\section{REFERENCES}

1. Aide S T (1980) "The reaction of a patient on the care he received in a hospital". American Journal of Nursing, Vol. 27, pp 24.

2. Alpert J J; Kosa J; Haggoity H; Robertson L.S; Neagarthy "Attitudes and satisfaction of low income families receiving a comprehensive patient care". American Journal of Public Health, 60 (3), pp 499509.

3. Anglen, Jeffery. Healey, William (1988) "Tibial Fracture and its management". Vol. 4, No. 2, Orthopedic Journal, pp 1527.

4. Clark, C C and Shea C A (1979) "Nursing care and patient Satisfaction". American Journal of Nursing, vol. 98, No. 72, pp 52-59.

5. Conant Lucy (1965) "Use of Bales interaction process, analysis to study nurse patient interaction". Nursing Research Vol.-14, No. 1, pp 98-100.

6. Gaigs Roberts, Green Michael (1989) "Dislocation of ankle Point". Contemporary Orthopedics, Vol. 19, No. 2, pp 10-12.

7. Eldas S Popiel (1975) "Nursing care of Patient" Nursing and Process of continuing education Vol. 34, pp 40-44.

8. Hill J (1997) "Patient satisfaction in nurse led Rheumatology clinic". Journal of Advanced Nursing, Vol. 25, pp 347-354.

9. Jones, Tracy (1992) "A approach to minor trauma”. Nursing Times, Vol. 86, No.27, pp 59-60, 64-66.

10. Korseh, B. M., Gozzi, Frances, W. (1990) "Gaps in doctors' patient interaction and patient satisfaction". Nursing Research, No. 42, pp 855-871.

11. Lauri, S., Lepisto, M. and Kappeli, S. (1997) "Patients need in hospital nurses and patients view". Journal of Advanced Nursing (1997) Vol. 25, pp. 339-346.

12. L.N. Risses (1975) "Development on an instrument to measure patient satisfaction with nursing care in primary care setting". Nursing Research, Vol. 24, No. 1, pp 45-50.

13. Monk, Helen de May "Fracture are never simple" RN April (1993), pp 2-6.

14. "Thinking of future and walking back to normal an explorative study of patients" experience during recovery from lower limb fracture. Journal of Advanced Nursing, Vol.28, No.6 pp 42-46.

15. Morse M. Janica, Bollor Joans, Hcitchins, Sally (1995) "Paradox of comfort". Vol. 44, No.2, pp 42-46.

16. Roberta "L, Messnea "What patients' really want from their nurses". A/N (1993), Vol.93, No. 8, pp 3841.

17. Sitizia. John, Neilwood "patient satisfaction with cancer chemotherapy nursing a review of literature". International Journal of Nursing. No. 35 (1998) pp 1-12.

18. Shield P.S., P. Morresson (1988) "Consumer satisfaction by psychiatric ward". Journal of Advanced Nursing, Vol. 23, No.3, pp 396-400.

19. Tetlle, Marry, Mac Millan Susan, "Pain and pain related side effects in an intensive care unit and in a surgical unit, nurses management". American Journal of Critical Care, Vol. 3, No. 1, pp 25-30.

20. Williams, Russel George V. "The Journal of trauma injury, infection and critical care". Vol. 47, No. 4, pp 1079-1082.

21. Zahir Kurdahi, Lena Sohev, A Williams (1991) "Patient satisfaction with the Nursing care in Alexandria, Egypt". Nursing Journal, Vol. 28, No. 6, pp 337-342. 